\title{
The VOIL Digital Transformation Competence Framework. Evaluation and Design of Higher Education Curricula
}

\author{
Klaus North ${ }^{1}$, Andreas Hermann ${ }^{2}$, Isabel Ramos ${ }^{3}$, Nekane Aramburu ${ }^{4}$, \\ and Daina Gudoniene ${ }^{5(\otimes)}$ \\ 1 Wiesbaden Business School, Bleichstraße 44, 65183 Wiesbaden, Germany \\ ${ }^{2}$ University of Münster, Schlossplatz 2, 48149 Münster, Germany \\ 3 University of Minho, R. da Universidade, 4710-057 Braga, Portugal \\ ${ }^{4}$ Deusto Business School, Hermanos Aguirre Kalea, 2, 48014 Bilbo, Spain \\ ${ }^{5}$ Kaunas University of Technology, Studentu 50, 51367 Kaunas, Lithuania \\ daina.gudoniene@ktu. It
}

\begin{abstract}
This paper presents a framework to evaluate and develop curricula for higher education in the context of digital transformation. Developing well guided learning journeys for the digital transformation is still a major challenge for educators. The proposed VOIL competence framework is grounded in dynamic capability theory. The VOIL competence framework has been developed by relating the DIGROW digital maturity framework to the European e-competence framework. The foundational architecture and rationale of the VOIL competence framework link learning objectives to the specific challenges of digital transformation of small and medium businesses. The authors also discuss the application of the VOIL competence model for evaluating and designing self-directed and personalized learning journeys.
\end{abstract}

Keywords: Digital transformation framework - Competence model · Curriculum development $\cdot$ Self-directed learning $\cdot$ Higher education

\section{Introduction}

Digital technologies are bringing about unprecedented change to business models, products, and services, transforming how people work and interact with customers, partners, and competitors $[6,7]$. The resulting digital transformation (DT) is not a recent trend but an ongoing paradigm leading to a digital change of society and economy at all levels [2]. For the individual organization, DT can be regarded as a process, which comprises incremental and disruptive changes enabled by digital technology. Vial [19] describes digital transformation as a process where digital technologies create disruptions triggering strategic responses from organizations that seek to alter their value creation paths, while managing the structural changes and organizational barriers that affect the positive and negative outcomes of this process. 
This point of view is aligned with conceptual approaches considering that digitalization transcends technology. As pointed out by several authors [1], DT implies the embeddedness of IT throughout organization, organizational processes and functions. Also, IT strategy becomes integrated with business strategy, giving rise to the novel concept of "digital strategy". According to Bharadwaj et al. [1] "the time is right to rethink the role of IT strategy, from that of a functional-level strategy - aligned but essentially always subordinate to business strategy - to one that reflects a fusion between IT strategy and business strategy. This fusion is herein termed digital business strategy". This view is also supported by other authors [12, 20]. In words of Kahre et al. [12] "digital business strategy reflects a new logic of competitive strategy where boundaries between business and IT strategy become blurred. Dynamically synchronized, business and IT are mutual drivers of strategic change, business value and ultimately competitive advantage". On the other hand, several authors argue that digital strategy relies on organizational capabilities [10, 20]. "The dynamism and complexity of the business and technology environment suggest that digital strategy is emergent, iterative, and influenced by evolving organizational capabilities" [20].

Such profound changes triggered by the speed of technological change requires an agile development and deployment of relevant skills and competencies of managers and staff. Workers must be able to interconnect the organizational challenges with the potentials of technology to come up with innovations that meet the business goals [9]. According to the European E-Skills Forum (2004), digital skills are understood to be the skills and capabilities that enable businesses to exploit opportunities provided by ICT, to ensure more efficient and effective performance, to explore new ways of conducting business and to establish new businesses.

With digital technologies also the way how people are learning is changing [15]. E-Learning allows ubiquitous and self-directed learning "everywhere" by choosing the time, place, media and content that best meets the learners goals, intention and wishes [11]. Data driven identification of learning gaps are the basis for creating personalized learning experiences increasingly based on open education resources available on mobile devices [5]. In this context the role of trainers, coaches and educators is changing. Šereš et al. [16] highlight the importance of preparing students for the challenges of digital transformation, especially those studying business informatics. Therefore, higher education agents need clear roadmaps for the most effective way to develop advanced digital skills that meet organizations' digital transformation needs.

In order to meet the needs for preparing students and staff in firms, particularly in SMEs this paper presents a digital transformation competence framework based on dynamic capabilities theory as will be explained below.

The development of the framework is part of the ongoing VOIL - Virtual Open Innovation Lab www.voil.eu. The project is implemented by partners from different European countries with the purpose of supporting small and medium enterprises (SME) to address the challenges of the digital transformation from a (dynamic) capability and competence perspective. The main objectives of the project are the following: 1) to provide a set of artefacts (i.e. tools, models, methods, etc.) that SMEs can apply to foster and propel their own digital transformation; 2) to provide a digital transformation competence framework 
and curriculum for higher education in order to guide the development of learning journeys aimed at acquiring and developing digital competences; 3) to disseminate these artefacts, the framework and curriculum to higher education students and SMEs via a dedicated digital platform.

The VOIL Digital Transformation Competence Framework and Curriculum is a tool to support educators in the higher education system, trainers and coaches as well as entrepreneurs, professionals and learners at large interested in designing and evaluating personalized and self-directed training that best fits the needs of their company and workers. The proposed curriculum is grounded in pedagogical strategies of self-directed learning [13]. It therefore represents an approach to customize personalized learning paths aligned with the needs and interests of the learners within a competence framework, linking organizational and individual perspectives of digital transformation. Instead of imposing a one-size-fits-all curriculum a guidance is provided to develop motivating selfdirected learning experiences. The VOIL framework is thought to be a guide for educators who want to either evaluate existing programs or to (re)design training programs focusing on the development of advanced digital skills.

In the following, this paper will first develop an understanding of digital transformation as a learning process related to dynamic capability theory. Subsequently the DIGROW digital maturity framework and the European e-competence framework will be explained and linked as a basis to create the VOIL Digital Transformation Competence Framework. The rationale of each of the four competence areas will be pointed out. Examples of learning objectives and possible learning journeys enabled by the Virtual Open Innovation Lab (VOIL) are provided. Section four sketches how to design self-directed and personalized learning journeys.

\section{Digital Transformation as a Learning Process}

Digital transformation is a learning process that requires integrating technology, business and learning strategies in an entrepreneurial-oriented organization. To understand such technology driven transformation processes Fountain's [8] technology enactment framework differentiates between objective and enacted technologies. Objective technology incorporates innovations such as analytics or the Internet, whereas enacted technology entails the use, design, and perception of those technologies by individuals within the organization. The role of technology, therefore, is dependent on the organization and what individuals within the organization make out of it. This observation is particularly relevant for SMEs where technology decisions depend on few people, their level of digital competencies and attitudes. Therefore, a competence framework for digital transformation and the related learning and development strategies have to allow an individualized appropriation of transformation capabilities related to an overall framework of digitally enabled growth.

Yeow et al. [20] found that as an organization shifts towards a digital strategy, misalignments between the emergent strategy and resources give rise to tension and requires alignment actions. These iteratively reconfigure organizational resources and refine strategy to respond to both changes in the environment and internal tensions. The dynamic capability approach provides a suitable analytical framework for organizations to purposefully align internal resources, processes, and structures to adapt to a changing 
environment. Sunday et al. [17] argue that using the concept of dynamic capabilities to examine the process of information communication technologies (ICT) adoption helps to unveil the recursive nature of the process. Following Teece [18] "For analytical purposes, dynamic capabilities can be disaggregated into the capacity (1) to sense and shape opportunities and threats, (2) to seize opportunities, and (3) to maintain competitiveness through enhancing, combining, protecting and, when necessary, reconfiguring the business enterprise's intangible and tangible assets" [18]. To act, a first step is to raise awareness of managers, workers, and students as future workers towards required capabilities, as well as opportunities/threats. Central to a successful transformation is the creation of a shared understanding of what "digitally enabled growth" means for the firm and subsequently develop and communicate a strategy.

In this transformation and learning journey individuals and organizations look for orientation, which can be provided by maturity models or frameworks. Maturity models allow the assessment of the current situation of a company as well as the identification of reasonable improvement measures [3] and serve as a guide through the transformation journey. Maturity can be defined as a measure to evaluate the capabilities of an organization regarding a certain discipline. Digital maturity means that a company has the necessary organizational capabilities to succeed in the digital transformation.

The VOIL competence framework is based on the DIGROW-Framework of digital maturity [14] which is visualized as a wheel of digitally enabled growth (see Fig. 1). The DIGROW-Framework serves to:

1. Raise awareness of owners, managers and employees of SMEs and students towards required capabilities, as well as opportunities/threats.

2. Create a shared understanding of what digitally enabled growth or digital transformation means.

3. Develop and communicate a strategy.

4. Anchor pilot initiatives in an overall "picture" of digitalization.

5. Compare own level of digital maturity with other firms.

6. Define learning objectives.

The theoretical foundation of the framework is Teece's [18] model of dynamic capability development. In their empirical study, Pavlou and El Sawy [21] deepened the understanding of how dynamic capabilities are developed and they proposed four steps: sensing, learning, integration, and coordination. These steps highlight the importance of managing knowledge and learning in digital transformation and of coping with turbulent and disruptive environments. A shortcoming in SMEs is that owners and managers are aware of growth potentials but often lack an explicit strategy, and if they have a strategy, they do not communicate that strategy to employees. That is why in the proposed model an intermediate step is inserted between Teece's "sensing" and "seizing": the step of strategy development and communication, which is related to Pavlou and El Sawy's [21] learning and integration.

The "DIGROW" framework, therefore, contains four dimensions, which can be seen as challenges (e.g. what are our challenges to sense digitally enabled growth potentials?) or competence areas or capabilities (e.g. do we have the capability to sense digitally enabled growth potentials?). Both views are useful in a self-assessment or in developing 
personalized learning paths. Along the lines of Teece's [18] micro-foundations of enterprise performance, North et al. [14] have defined four capacities for each of the four competency areas. Each of these capacities can be evaluated at five levels described by an anchor statement. It thus serves as an initial self-assessment as the basis for defining learning objectives.

The "DIGROW" framework is structured as follows:

1. Sensing digitally enabled growth potentials: Searching for digitally enabled growth opportunities, understanding, and developing digital customer needs, sensing technology driven opportunities, use of external sources for digital innovation.

2. Developing a digitally enabled growth strategy and mindset: Digitally enabled growth strategy, digital leadership, digital mindset (attitudes \& behavior's), empowered employees.

3. Seizing digitally enabled growth potentials: Digitally enabled business models, digital market presence, digital customer experience, agile implementation/deployment of digitization initiatives.

4. Managing resources for digital transformation: Digital skills \& learning, digital processes, digital technology \& security, digital investments.

\section{The VOIL Digital Transformation Competence Framework: Relating the DIGROW Framework to the European e-Competence Framework}

The European e-Competence Framework (e-CF) version 3.0 [4] provides a reference of 41 competencies as required and applied at the Information and Communication Technology (ICT) workplace, using a common language for competences, skills and capability levels that can be understood across Europe. In the framework 'Competence is a demonstrated ability to apply knowledge, skills and attitudes for achieving observable results. The structure of the 41 competencies follows a logic of an ICT project with the phases plan - build - run - enable - manage. The framework, therefore, does not fully cover competencies needed for the digital transformation of companies.

For the VOIL Digital Transformation Competency Model the DIGROW dimensions have been matched to the 41 e-competencies. The result is displayed in Fig. 1. The result shows that the e-competencies are not evenly distributed across the DIGROW sections. Business and transformation related competencies are underrepresented in relation to ICT development and deployment. For the sections "Digital mindset" and "digitally empowered employees" there are no corresponding e-competencies. We therefore propose 4 additional competencies related to developing a shared vision, commitment, autonomy in decision making and self-organization. Educators are invited to customize the repertoire of competencies according to their specific curricular needs, i.e. add further business relevant competencies or delete competencies.

Based on the above foundations the following architecture of the VOIL competence framework is proposed:

- Competence areas are the highest-level categorization of competencies and are, therefore, more stable over time. The VOIL curriculum focuses on four competency areas: 


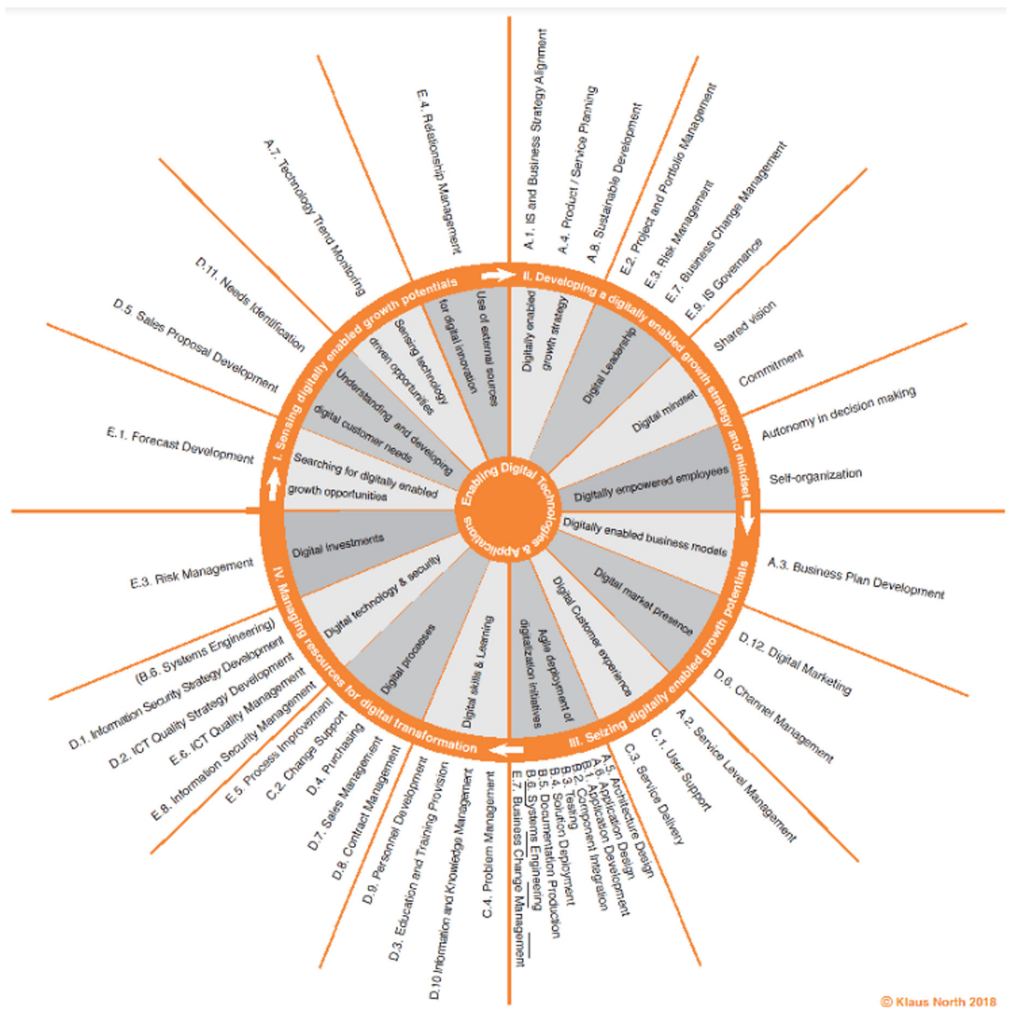

Fig. 1. European e-competence framework 3.0 related to the wheel of digitally enabled growth.

"Sensing digitally enabled growth potentials", "Developing a digitally enabled growth strategy and mindset", "Seizing digitally enabled growth potentials \& transformation" and "Managing resources for digital transformation".

- Competence categories specify the actual competencies to be developed. The VOIL curriculum includes eight competency categories that must be attained at least at the Awareness level (knowledge needs to be recalled when needed) and desirably at the Novice level (the learner needs to have experienced situations and cases). These categories are the basis for defining the learning objectives of the training modules.

- Competence is a demonstrated ability to apply knowledge, skills, and attitudes for achieving observable results (European e-Competence Framework). It is an integrative concept that refers to cognitive and metacognitive skills as well as values and attitudes. Since competencies tend to be more vulnerable to changes in technology and, therefore, less stable, the competencies are listed in this document as examples (Table 1).

In the following, we will explain the rationale of each of the four competence areas, relate these to competencies of the European e-competence framework and propose 
Table 1. The VOIL digital transformation competence framework.

\begin{tabular}{|c|c|c|c|c|}
\hline Areas & $\begin{array}{l}1 \text { Sensing digitally } \\
\text { enabled growth } \\
\text { potentials }\end{array}$ & $\begin{array}{l}2 \text { Developing a digitally } \\
\text { enabled growth strategy } \\
\text { and mindset }\end{array}$ & $\begin{array}{l}3 \text { Seizing digitally } \\
\text { enabled growth potentials } \\
\& \text { transformation }\end{array}$ & $\begin{array}{l}4 \text { Managing resources } \\
\text { for digital } \\
\text { transformation }\end{array}$ \\
\hline Categories & $\begin{array}{l}\text { 1.1. Understand and } \\
\text { monitor digital } \\
\text { technologies and their } \\
\text { business potentials } \\
\text { 1.2. Develop digital } \\
\text { customer needs }\end{array}$ & $\begin{array}{l}\text { 2.1. Review and design } \\
\text { digital business strategy } \\
\text { and business models } \\
\text { 2.2. Develop a digital } \\
\text { transformation culture }\end{array}$ & $\begin{array}{l}\text { 3.1. Transform the } \\
\text { organization } \\
\text { 3.2. Design/implement } \\
\text { digital market presence } \\
\text { and customer experience }\end{array}$ & $\begin{array}{l}\text { 4.1. Implement and } \\
\text { manage digital } \\
\text { processes } \\
\text { 4.2. Manage digital } \\
\text { risks and cybersecurity }\end{array}$ \\
\hline Competencies & $\begin{array}{l}\text { A.7. Technology trend } \\
\text { monitoring } \\
\text { E.1. Forecast } \\
\text { development } \\
\text { D.11. Needs } \\
\text { identification } \\
\text { D.5. Sales proposal } \\
\text { development }\end{array}$ & $\begin{array}{l}\text { A.1. IS and business } \\
\text { strategy alignment } \\
\text { A.3. Business plan } \\
\text { development } \\
\text { A.4. Product/ service } \\
\text { planning } \\
\text { A.8. Sustainable } \\
\text { development } \\
\text { E.9. IS governance } \\
\text { D.9. Personnel } \\
\text { development } \\
\text { D.3. Education and } \\
\text { training provision }\end{array}$ & $\begin{array}{l}\text { E.7. Business change } \\
\text { management } \\
\text { E.2. Project and Portfolio } \\
\text { management } \\
\text { D.10. Information and } \\
\text { knowledge management } \\
\text { C.4. Problem } \\
\text { management } \\
\text { B.4. Solution deployment } \\
\text { (see also M7) } \\
\text { E.4. Relationship } \\
\text { management } \\
\text { D.12. Digital marketing } \\
\text { D.6. Channel } \\
\text { management }\end{array}$ & $\begin{array}{l}\text { A.5. Architecture } \\
\text { design } \\
\text { A.6. Application } \\
\text { design } \\
\text { B.1. Application } \\
\text { development } \\
\text { B.2. Component } \\
\text { integration } \\
\text { B.3. Testing } \\
\text { B.4. Solution } \\
\text { deployment } \\
\text { B.5. Documentation } \\
\text { production } \\
\text { B.6. Systems } \\
\text { engineering } \\
\text { D.1. Information } \\
\text { security strategy } \\
\text { development } \\
\text { D.2. ICT quality } \\
\text { strategy development } \\
\text { E.6. ICT quality } \\
\text { management } \\
\text { E.8. Information } \\
\text { security management } \\
\text { E.3. Risk management }\end{array}$ \\
\hline
\end{tabular}

learning objectives. Examples of possible learning journeys enabled by the Virtual Open Innovation Lab (VOIL) are given.

\subsection{Sensing Digitally Enabled Growth Potentials}

To sense digitally enabled growth potentials, firms would need an intention to seek out and understand external information in order to identify new opportunities. In operational terms, SMEs must implement mechanisms and processes for scanning, observing and understanding changes in the business environment. Learning objectives relate to understanding the main digital technologies \& applications, assess their business potentials and monitor technology trends. Digitally enabled innovation and growth opportunities arise from understanding and developing digital customer needs and from identifying technology-driven opportunities. A particularly fruitful source can be the use of external knowledge for digital innovation: (potential) customers, universities, research centres, "the crowd", partners in the "ecosystem". This competence area encompasses two 
competence categories: Understand and monitor digital technologies and their business potential and understand and develop digital customer needs (Table 2).

Table 2. Competencies and learning objectives to sense digitally enabled growth potentials

\begin{tabular}{l|l|l|l}
\hline Categories & $\begin{array}{l}\text { Related competencies } \\
\text { of European } \\
\text { e-competence } \\
\text { framework }\end{array}$ & Learning objectives & $\begin{array}{l}\text { Examples of learning } \\
\text { journeys enabled by the } \\
\text { VOIL platform }\end{array}$ \\
\hline $\begin{array}{l}\text { Understand and } \\
\text { monitor digital } \\
\text { technologies and } \\
\text { their business } \\
\text { potentials }\end{array}$ & $\begin{array}{l}\text { A.7. Technology trend } \\
\text { monitoring }\end{array}$ & $\begin{array}{l}\text { Understand the main } \\
\text { digital technologies \& } \\
\text { applications, assess } \\
\text { their business } \\
\text { potentials, monitor } \\
\text { technology trends }\end{array}$ & $\begin{array}{l}\text { DIGROW-assessment, } \\
\text { simulators }\end{array}$ \\
\hline $\begin{array}{l}\text { Understand and } \\
\text { develop digital } \\
\text { customer needs }\end{array}$ & $\begin{array}{l}\text { E.1. Forecast } \\
\text { development } \\
\text { D.11. Needs } \\
\text { identification } \\
\text { D.5. Sales proposal } \\
\text { development }\end{array}$ & $\begin{array}{l}\text { Identify and develop } \\
\text { digital needs and } \\
\text { expectations of } \\
\text { (potential) customers, } \\
\text { search for new value } \\
\text { generation and growth } \\
\text { opportunities }\end{array}$ & $\begin{array}{l}\text { DIGROW-assessment, } \\
\text { simulators }\end{array}$ \\
\hline
\end{tabular}

\subsection{Developing a Digitally Enabled Growth Strategy and Mindset}

Based on the exploration of possible futures, firms will have to develop an understanding of how digital solutions will help to deliver the firm's objectives and to review their strategy regarding digitalization. The question of how SMEs can succeed in the digital environment requires understanding what strategic orientation best equips SMEs to compete in that environment.

It is crucial that leaders (owner and/or managers of SMEs) recognize the potential of digitally enabled growth. Creating a shared understanding of how the digital world "ticks" is a prerequisite for motivating employees and developing a forward-looking attitude towards digitalization followed by a broad development of new behavior's ("digital mindset"). In such a digitally oriented organization, employees are empowered and encouraged to experiment with digital initiatives. This competence area includes the following competence categories: Review and design digital business strategy and business models and develop a digital transformation culture (Table 3). 
Table 3. Competencies and learning objectives to develop a digitally enabled growth strategy and mindset.

\begin{tabular}{|c|c|c|c|}
\hline Categories (modules) & $\begin{array}{l}\text { Related competencies } \\
\text { of European } \\
\text { e-competence } \\
\text { framework }\end{array}$ & Learning objectives & $\begin{array}{l}\text { Examples of learning } \\
\text { journeys enabled by } \\
\text { the VOIL platform }\end{array}$ \\
\hline $\begin{array}{l}\text { Review and design } \\
\text { digital business } \\
\text { strategy and business } \\
\text { models }\end{array}$ & $\begin{array}{l}\text { A.1. IS and business } \\
\text { strategy alignment } \\
\text { A.3. Business plan } \\
\text { development } \\
\text { A.4. Product/service } \\
\text { planning } \\
\text { A.8. Sustainable } \\
\text { development }\end{array}$ & $\begin{array}{l}\text { Analyze current } \\
\text { position of firm, } \\
\text { develop a digital } \\
\text { strategy, review \& } \\
\text { modify existing } \\
\text { business models, } \\
\text { creation of new } \\
\text { business models, } \\
\text { develop a business } \\
\text { plan }\end{array}$ & $\begin{array}{l}\text { DIGROW- } \\
\text { self-assessment, } \\
\text { co-creation canvas, } \\
\text { procedure model }\end{array}$ \\
\hline $\begin{array}{l}\text { Develop a digital } \\
\text { transformation culture }\end{array}$ & $\begin{array}{l}\text { E.9. IS Governance } \\
\text { E.2. Project and } \\
\text { portfolio management } \\
\text { E.3. Risk management } \\
\text { E.7. Business change } \\
\text { management } \\
\text { D.9. Personnel } \\
\text { development } \\
\text { D.3. Education and } \\
\text { training provision } \\
\text { D.10. Information and } \\
\text { knowledge } \\
\text { management } \\
\text { C.4. Problem } \\
\text { management }\end{array}$ & $\begin{array}{l}\text { Digital leadership, } \\
\text { development of a } \\
\text { digital mindset, } \\
\text { empower employees } \\
\text { for digital initiatives }\end{array}$ & $\begin{array}{l}\text { "Learning to grow" } \\
\text { methodology } \\
\text { co-creation canvas }\end{array}$ \\
\hline
\end{tabular}

\subsection{Seizing Digitally Enabled Growth Potentials and Transformation}

To exploit identified opportunities or mitigate threats of digitalization, SMEs have to revise business strategies and decide whether to adapt current business models or develop new ones. This is linked to investment choices and preparedness to enter into new fields, such key elements are digital market presence and digital customer experience leading to new ways of value creation, value capture and value offer. Depending on their current stage of development, SMEs might perceive business potentials of digitalization but acknowledge their current unpreparedness for implementing the required new technologies. Therefore, the ability to deploy digitalization initiatives is crucial to seizing perceived opportunities. This might include small pilot projects and/or methodologies for agile product and service development, such as design thinking. The competence categories that this competence area integrates are as follows: Transform the organization and Design/implement digital market presence and customer experience (Table 4). 
Table 4. Competencies and learning objectives to seize digitally enabled growth potentials \& transformation the organization

\begin{tabular}{l|l|l|l}
\hline Categories & $\begin{array}{l}\text { Related competencies } \\
\text { of European } \\
\text { e-competence } \\
\text { framework }\end{array}$ & Learning objectives & $\begin{array}{l}\text { Examples of } \\
\text { learning journeys } \\
\text { enabled by the } \\
\text { VOIL platform }\end{array}$ \\
\hline $\begin{array}{l}\text { Transform the } \\
\text { organization }\end{array}$ & $\begin{array}{l}\text { E.7. Business change } \\
\text { management } \\
\text { B.4. Solution } \\
\text { deployment (see also } \\
\text { M7) }\end{array}$ & $\begin{array}{l}\text { Change management, } \\
\text { process model of } \\
\text { digital transformation, } \\
\text { digitalization road } \\
\text { map, co-creation, } \\
\text { collaboration with } \\
\text { external partners, agile } \\
\text { deployment of } \\
\text { initiatives }\end{array}$ & $\begin{array}{l}\text { DIGROW- } \\
\text { self-assessment, } \\
\text { Co-creation canvas, } \\
\text { procedure model } \\
\text { "Learning to grow" } \\
\text { methodology }\end{array}$ \\
\hline $\begin{array}{l}\text { Design/implement } \\
\text { digital market } \\
\text { presence and } \\
\text { customer experience }\end{array}$ & $\begin{array}{l}\text { D.12. Digital } \\
\text { marketing } \\
\text { D.6. Channel } \\
\text { management }\end{array}$ & $\begin{array}{l}\text { Business analytics, } \\
\text { digital marketing, } \\
\text { channel management }\end{array}$ & \\
\hline
\end{tabular}

\subsection{Managing Resources for Digital Transformation}

Managing threats and transforming the organization requires, the continuous alignment and realignment of resources such as knowledge of people, technologies which are embedded in processes and financial investments. Finally, this competence area encompasses the following competence categories: Implement and manage digital processes comprising the capacity to digitalize the organization's processes in order to achieve higher efficiency and efficacy in the execution of the business goals. As well as competencies to manage digital risks and cybersecurity, i.e. the adoption of technologies that guarantee the security in business processes, data, and customers, against possible external attacks and/or an inadequate use of data (Table 5).

\section{Outlook: Designing Self-directed and Personalized Learning Journeys}

As the main focus of this paper is to present and explain the foundations of the VOIL competence framework in this section we will provide an outlook how this framework can be used by educators or instructional designers and learners to design customized learning paths (CLP). CLP allow learners to co-design their learning with educators rather than simply comply with the directions and expectations of a traditional education process. Customized learning path help learners in taking ownership of their learning, finding greater meaning and purpose, and becoming increasingly independent in their learning skills. 
Table 5. Competencies and learning objectives to manage resources for digital transformation.

\begin{tabular}{|c|c|c|c|}
\hline Categories & $\begin{array}{l}\text { Related competencies } \\
\text { of European } \\
\text { e-competence } \\
\text { framework }\end{array}$ & Learning objectives & $\begin{array}{l}\text { Examples of learning } \\
\text { journeys enabled by } \\
\text { the VOIL platform }\end{array}$ \\
\hline $\begin{array}{l}\text { Implement and } \\
\text { manage digital } \\
\text { processes }\end{array}$ & $\begin{array}{l}\text { E.7. Business change } \\
\text { management } \\
\text { A.5. Architecture } \\
\text { design } \\
\text { A.6. Application design } \\
\text { B.1. Application } \\
\text { development } \\
\text { B.2. Component } \\
\text { integration } \\
\text { B.3. Testing } \\
\text { B.4. Solution } \\
\text { deployment } \\
\text { B.5. Documentation } \\
\text { production } \\
\text { B.6. Systems } \\
\text { engineering }\end{array}$ & $\begin{array}{l}\text { Design and deployment } \\
\text { of new processes in } \\
\text { different areas of the } \\
\text { firm }\end{array}$ & Procedure model \\
\hline $\begin{array}{l}\text { Manage digital } \\
\text { risks and } \\
\text { cybersecurity }\end{array}$ & $\begin{array}{l}\text { (B.6. Systems } \\
\text { engineering) } \\
\text { D.1. Information } \\
\text { security strategy } \\
\text { development } \\
\text { D.2. ICT quality } \\
\text { strategy development } \\
\text { E.6. ICT Quality } \\
\text { management } \\
\text { E.8. Information } \\
\text { security management } \\
\text { E.3. Risk management }\end{array}$ & $\begin{array}{l}\text { Deal with digital risks } \\
\text { and improve } \\
\text { information security } \\
\text { and reliability }\end{array}$ & Simulators \\
\hline
\end{tabular}

The VOIL competence model is constructed in a way that it enables the design of these personalized learning journeys. To allow this kind of configurability, a component-based architecture of the competence model is needed. Similar to the idea of decoupling applications in software engineering, the competence model aims at decoupling its elements into layers of different levels of abstraction. This layered component-based structure allows two things. First, components can be replaced, extended, or adjusted if changes in the context of the digital transformation occur, for instance, if new technologies demand the development of new Competences. Second, this structure sets the foundation for a flexible design of curricula. Thereby, tailored competence collections can be designed and implemented. Depending on the needs of a study program, a firm or an individual learner relevant competence can be selected and related to educational resources. Let us 
consider an example: Results of the DIGROW digital maturity assessment might point to the need to better "understand and monitor digital technologies and their business potentials" in the case of block chain. On the VOIL platform learners might use the block chain simulator to understand how block chain works and guided by educators or interacting with peers might learn to assess concrete business potentials.

Through the application of a set of strategies and guidelines for deriving tailored competence collections, a specific instance of the competence model can be created. These strategies and guidelines help educators in their task of creating their own digital transformation curriculum in a structured way. The competence model together with strategies and guidelines to apply the model and derive curricula compose the so-called Meta Level. This level can be interpreted as a generic configurable reference perspective. By applying strategies and guidelines, educators are equipped with a toolset to compile customized curricula. This instantiation leads to the definition and selection of actual modules, learning objectives, learning experiences and courses, which together make up the Instance Level (see Fig. 2).

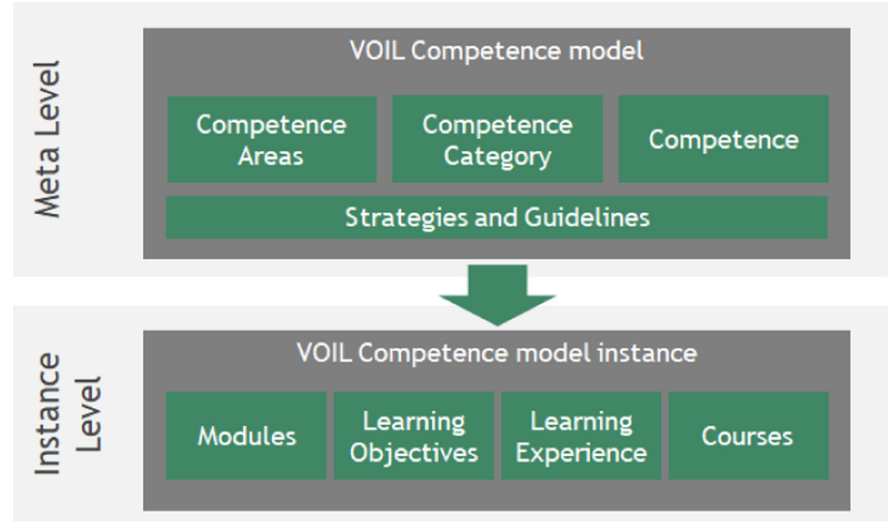

Fig. 2. Two levels of customized curricula design.

The instantiation process leads to the creation of these personalized learning journeys, which are tailored to an organization's needs and starting point. Instead of being confronted with a one-size-fits-all curriculum and learning material, learners are equipped with their personal need-based curriculum.

Therefore, a plethora of different learning journeys will exist. On the VOIL platform these journeys shall be augmented by selected material in form of simulators, tools, methods, etc. Therefore, competence framework and the concept of instantiating it set the foundational architecture for the VOIL platform.

\section{Conclusions}

The VOIL Digital Transformation Competence Framework links two established frameworks: The DIGROW Framework of digital maturity and the European e-Competence 
Framework. In the matching of both frameworks it became obvious that the European e-Competence Framework in particular business and transformation related competencies are underrepresented in relation to ICT development and deployment. Therefore, additional competencies have been proposed, which still need to be validated. The VOIL Competence Framework fills a gap of research as it overcomes two deficits of systematic skill compilations for digital transformation. Firstly, it has a wholistic business focus representing all phases of digitally enabled growth. Secondly it is grounded in dynamic capability theory, which currently is the accepted basis to explain sustainable competitiveness in turbulent environments. As the VOIL project is initial phase test of the frameworks have not yet been performed. Furthermore, the above sketched instantiation approach to define and select competence collections, learning objectives and to create learning experiences and courses needs still to be matured.

Acknowledgments. The paper is developed as part of the project VOIL - "Virtual Open Innovation Lab", the European Union program Erasmus+ (2019-1-DE01-KA203-005021). www.voil.eu.

\section{References}

1. Baradhwaj, A., El Sawy, O.A., Pavlou, P.A., Venkatraman, N.: Digital business strategy: towards a next generation of insights. MIS Q. 37(2), 471-482 (2013)

2. Bounfour, A.: Digital Futures Digital Transformation. Springer, Heidelberg (2016)

3. Becker, J., Knackstedt, R., Pöppelbuß, J.: Developing maturity models for IT management. Bus. Inf. Syst. Eng. 1(3), 213-222 (2009)

4. CEN: European Norm (EN) 16234-1 European e-Competence Framework (e-CF) (2016). https://www.ecompetences.eu/

5. EAEA: The future of adult learning in Europe. Background paper - European Association for the Education of Adults (2019). https://eaea.org/wp-content/uploads/2019/12/The-future-ofadult-learning-in-Europe.pdf. Accessed 21 Apr 2020

6. European E-Skills Forum: E-Skills for Europe: Towards 2010 and beyond (2004). https:// www.bvekennis.n1/Bibliotheek/09-0484_e-skills-forum-2004-09-fsr.pdf

7. EU (European Commission): Digital Transformation Scoreboard 2018 (2018). https://op.eur opa.eu/en/publication-detail/-/publication/683fe365-408b-11e9-8d04-01aa75ed71a1

8. Fountain, J.E.: Prospects of the Virtual State. University of Tokyo 21st Century COE program "Invention of Policy Systems in Advanced Countries" (2004)

9. IDC-SAP: The next steps in digital transformation. How small and midsize companies are applying technology to meet key business goals (2017). http://news.sap.com/wp-content/ blogs.dir/1/files/SAP_IDC_infobrief_SMB_DX_102016.pdf

10. Galliers, R.D.: Further developments in information systems strategizing: unpacking the concept. In: Galliers, R.D., Currie, W.L. (eds.) The Oxford Handbook of Management Information Systems: Critical Perspectives and New Directions, pp. 329-345. Oxford University Press, Oxford (2011)

11. Haenisch, S.: The Future of Learning - Top 7 Predictions for 2030 (2017). https://blogs.sap. com/2017/11/22/the-future-of-learning-top-7-predictions-for-2030/. Accessed 15 Apr 2020

12. Kahre, C., Hoffmann, D., Ahlemann, F.: Beyond business-IT alignment - digital business strategies as a paradigmatic shift: a review and research agenda. In: Proceedings of the 50th Hawaii International Conference on System Sciences, pp. 4706-4715 (2017) 
13. Knowles, M.S.: Self-Directed Learning. Association Press, New York (1975)

14. North, K., Aramburu, N., Lorenzo, O.: Promoting digitally enabled growth in SMEs: a framework proposal. J. Enterp. Inf. Manag. 33(1), 238-262 (2019). https://doi.org/10.1108/JEIM04-2019-0103

15. OECD: The Future of Education and Skills. Education 2030, p. 4 (2018). https://www. oecd.org/education/2030/E2030\%20Position\%20Paper\%20(05.04.2018).pdf. Accessed 20 Apr 2020

16. Šereš, L., Tumbas, P., Matkovic, P., Pavlićević, V.: Embedding digital competencies in business informatics curriculum. In: 2nd Conference on Innovative Teaching Methods (ITM 2017), 28-29 June 2017, University of Economics Varna, Bulgaria (2017)

17. Sunday, C.E., Vera, C.: Examining information and communication technology (ICT) adoption in SMEs: A dynamic capabilities approach. J. Enterp. Inf. Manag. 31(2), 338-356 (2018)

18. Teece, D.J.: Explicating dynamic capabilities: the nature and microfoundations of (sustainable) enterprise performance. Strateg. Manag. J. 28(4), 1319-1350 (2007)

19. Vial, G.: Understanding digital transformation: a review and a research agenda. J. Strateg. Inf. Syst. 28, 118-144 (2019)

20. Yeow, A., Soh, C., Hansen, R.: Aligning with new digital strategy: a dynamic capabilities approach. J. Strateg. Inf. Syst. 27, 43-58 (2018)

21. Pavlou, P.A., El Sawy, O.A.: Understanding the elusive black box of dynamic capabilities. Decis. Sci. 42(1), 239-273 (2011) 